juundice in newhorn monkeys. N Lingl J Med. 283.1136 (1970)

27. Levillain. P., Odievre. M., Luzeau, R.. and lemonnier. A.: Possibilites d’inhibition de la glucuronoconjugaison de la hilirubine en fonction de la teneur en acides gras libres du lait maternel. Biochim. Biophys. Acta. 264 538 (1972)

28. Lewi, S.. Walter, P., and Clarke, T. K.. Nllatement maternel el hyperhilirubinemie du nouveau-ne. Biol. Neonat. (Basel), 7: 294 (1964).

29. Lowry, O. H., Roschrough, N. J., Farr, A. I... and Randall, R. I.: Protei measurement with the Folin phenol reingent. J. Biol. Chem. 193: 26.5 (1951).

30. Mishkin, S. Stein. 1.. (jatmaitan. K.. Fleischner. G.. and Arias, I. M.: On the structure and function of $Z$ protein. Fith Meeting of the International Association for the Study of the liver $\mathrm{p}$ 32.1972 Versisilles. [Abstr.].

31. Newman. A. I. and Gross. S.: Hyperhilirubinemia in hreastfed infants Pediatrics, 32: $995(1963)$

32. Ockner, R. K.: Fatty acid binding protein in cytosol of liver intestinal mucosa and other tissues. Fifth Meeting of the International Association for the Study of the liver. p. XIII, 1972, Versailles, [Abstr.].

33. Ockner, R. K.. Manning, J. A., Poppenhausen, R. B., and Ho, W. K. L.: A binding protem for latty acids in cytemol of intestinal mucosia, liver, myocar dium and other tissues. Science, 177.56 (1972)

34. Ockner. R. K.. Pittman. J. P.. and Yager, J. L.: Differences in the intestinal absorption of saturated and unsaturated long chain fatts acids (iastroenterology, 62: $981(1972)$

35. Odière, M.: I ictere du lait de femme: Progres recents. Arch. I ranc. Pediat.. 3t: 569 (197.3).

Copvright (c) 1976 International Pediatric Rescarch Foundation, Inc.
36. Ramos, A Silverberg, $M$ and Stern, L. Pregnanediols and neonatal hyperbilirubinemia Amer I. Dis Child 111. 353 (1966)

37. Severi. F.. Rondini. (i.. Zaterio, S.. and Vegni. M.: Prolonged neonatal hiperhilirubinemia and pregnane $(3 \alpha), 2()(\beta)$-diol in maternal milk. Helv. Patediat. Acta. 25:517(1970)

38. Starinsks, R., and Shalrir. 1..: Displacement of alhumin-bound biliruhin bs free fatty acids: Implicattions for neonatal hyperbilirubinemia Clin. Chim. Actat. 29. 311 (1970).

39. Stichm, E. R., and Ryan, J.: Breast-milk jaundice. Amer. J. Dis. (hild. I109: 212 $(1965)$.

40. Thiessen. H., Jacobsen, J., and Brodersen, R.: Diplacement of al humin-bound bilirubin by fatts acids. Acta Paediat. Scand. 61: 285 (1972).

41. We wish to thank Miss Therese Fournier for her technical assistance.

42. Since this paper was submitted, one of the authors has undertaken a prospective study in a maternits hospital: 1.000 women will be sampled. The delection of pathological milks is done with a stained reatction using Nile blue (l.usatu R. Levilkain $P$. Odievre $M$, and Lemonnier $A$. Depistage des litits maternels inhibiteurs de la glucuroconjugaison de la bilirubine par une reiction coloree. Arch. Francf. Pediat.. 30: 573 (1973)). The study's purpose is to see whether some inhibitory milks will be found in the absence of jaundice.

43 Requests for reprints should be addressed to A Foliot, M.D. I niti de Recherches de Biolugic Inimale et Techniques txperimentales, INSi:RM. 1-36. 17 rue de Jer-a-Moulin. 7500 s Paris (1-rance)

44. Accepted for publication December 18. 1975
Pediat. Res. 10: 598-609 (1976)
Homocystinuria kidney

liver 5,10-methylenetetrahydrofolate reductase deficiency plasma urine

\title{
Morphologic Studies in a Patient with Homocystinuria due to 5,10-Methylenetetrahydrofolate Reductase Deficiency
}

\author{
YASHPAI, S. KANWAR, JOSE R. MANAI.IGOD, AND PAUI. W. K. WONG;
}

Department of Pediatrics and Departme'nt of Pathology, A hraham Lincoln. School of Medicine, University of Illinois,

Chicago. Illinois. U'S A

\section{Fxtract}

Biochemical and morphologic studies on a patient with homocystinuria due to a deficiency of 5,10-methylenetetrahydrofolate reductase ( $\mathrm{E}(\mathrm{C}, 1.1 .1 .68$ ) were performed.

The concentrations of homocystine in the patient's plasma and urine were $2.97 \mu \mathrm{mol} / \mathrm{dl}$ and $44.67 \mu \mathrm{mol} / 24 \mathrm{hr}$, respectively. Activities of 5,10-methylenetetrahydrofolate reductase (expressed as nanomoles of formaldehyde formed per $\mathrm{hr}$ per $\mathrm{mg}$ of protein) in cultured skin fibroblasts and liver tissue were 0.53 (control: 5.14 ) and 0.00 (control: 13.80 ), respectively.

The major abnormalities were found in the arterial bed, consisting of intimal hyperplasia, fragmentation, and disruption of elastic lamellae and subcellular changes in the endothelial cells. Extensive thrombosis was observed. The brain and the liver also showed widespread pathologic changes. In the former, neuronal loss and cellular damage were prominent and extensive. Diffuse demyelination with moderate astrocytosis was found: but demyelination was out of proportion to the vascular changes. Hirano bodies in the cortical neurons and crystalline and lamellar bodies in the Purkinje cells were observed. In the liver, there were fatty change and mild to moderate portal fibrosis. Bizarre, giant mitochondria and membrane-bound multivesicular bodies were found. Mild pathologic changes were also observed in the striated muscles and the kidneys. Focal fragmentation, disruption, and smearing of the $\%$. discs and disorganization of the myofilaments were found in the skeletai muscles. The kidneys showed shrunken glomeruli, thickened basement membranes, and swelling of epithelial as well as endothelial cells.

\section{Speculation}

The morphologic abnormalities under light or electron microscopy in this patient with $\mathbf{5 , 1 0}$-methylenetetrahydrofolate reductase deficiency were strikingly similar to those reported in patients with cystathionine- $\beta$-synthase deficiency and with $N^{\prime 5}$-methyltetrahydrofolate homocystine methyltransferase deficiency. The common denominator in all these disorders is homocystinemia. It is postulated that the widespread vascular lesions are produced by the "toxic" effect of homocystine and that the pathologic changes in other organs are the result of ischemia and thrombosis as well as a possible direct effect of homocystine. 
Homocystinuria may be due to a deficiency of cystathionine- $\beta$ synthase, $N^{5}$-methyltetrahydrofolate homocystine methyltransferase (or abnormal vitamin $B_{12}$ metabolism) (30), 5, 10methylenetetrahydrofolate reductase, and the administration of 6-azauridine triacetate (14). Clinically, patients with cystathionine$\beta$-synthase deficiency have ectopia lentis, skeletal deformities, marfanoid features, thromboembolic tendency, and mental retardation (1). In patients with deficiency of $N^{5}$-methyltetrahydrofolate homocystine methyltransferase and 5,10-methylenetetrahydrofolate reductase, ectopia lentis and severe skeletal abnormalities have not been observed $(4,10,16)$. Concurrent biochemical and pathologic studies in the various types of homocystinuria may reveal similarities or differences which may provide insight in the pathogenesis of the observed abnormalities.

This communication records the first ultrastructural study in a patient with 5,10-methylenetetrahydrofolate reductase deficiency.

\section{MATERIALS AND METHODS}

The subject of this study was a 10-year-old Caucasian female who had delayed psychomotor development, severe mental retardation, genu valgum, and mild spastic paraparesis. Detailed ophthalmologic examination on several occasions did not show any abnormality. The proportion of her upper and lower segments was normal as were her upper limbs and fingers. X-ray showed no skeletal deformity. She was admitted to the University of Illinois Hospital at a terminal stage, with respiratory difficulties, cyanosis, seizures, and semicoma. Death occurred within $24 \mathrm{hr}$ of admission and autopsy was performed within I hr after death.

She had three mentally retarded sisters with similar clinical illness, four normal brothers, and three normal sisters. Her clinically normal parents were of Irish ancestry and no consanguinity was recorded.

Two of the affected sisters died in other hospitals without a definitive diagnosis and in one of them the autopsy showed cerebral thrombosis, hydrocephalus, and disseminated focal demyelination.

Blood, urinary, and tissue amino acids were determined by ion exchange chromatography as previously described $(31,33)$. The methods of Mudd and his associates $(22,23)$ were used for the assay of cystathionine- $\beta$-synthase, $N^{5}$-methyltetrahydrofolate homocystine methyltransferase, and 5,10-methylenetetrahydrofolate reductase. Tissues obtained at autopsy were immediately frozen and maintained at $-40^{\circ}$ until enzyme assays.

Tissues for light microscopy were fixed in $3.7 \%$ formaldehyde, sectioned, and stained with hematoxylin-eosin, Masson trichrome. elastica (Hart), Weil Klüver-Barrera, and Prussian blue stains.

For electronmicroscopy, samples of tissues were fixed in $4 \%$ glutaraldehyde buffered with cacodylate at $\mathrm{pH} 7.4$ for $4 \mathrm{hr}$, postfixed with $1 \%$ osmium tetroxide, dehydrated in graded alcohol, and embedded in Epon. Thick sections were stained with toluidine blue and thin sections were stained with uranyl acetate and lead citrate.

For comparison, specimens were also obtained from a 10-yearold girl $3 \mathrm{hr}$ after her accidental death.

\section{RESULTS}

The presence of homocystine in the urine and blood of this patient was demonstrated on many occasions. Table I shows the

Table 1. Amino acid concentrations ${ }^{1}$

\begin{tabular}{|c|c|c|c|c|c|c|c|c|}
\hline & \multicolumn{2}{|c|}{ Methionine } & \multicolumn{2}{|c|}{ Cystathionine } & \multicolumn{2}{|c|}{ Homocystine } & \multicolumn{2}{|r|}{ Cystine } \\
\hline & $\mathbf{P}$ & $\mathrm{C}$ & $\mathrm{P}$ & $\mathrm{C}$ & $P$ & $\mathrm{C}$ & $\mathrm{P}$ & $\mathrm{C}$ \\
\hline Plasma ${ }^{2}$ & 2.39 & $2.19 \pm 0.65^{3}$ & ND & ND & 2.97 & ND & 2.32 & $2.79 \pm 0.98^{3}$ \\
\hline Urine & 17.70 & $10.38 \pm 8.07^{3}$ & ND & $4.0^{5}$ & 44.67 & ND & 13.22 & $21.35 \pm 10.51^{3}$ \\
\hline Frontal 'sbe ${ }^{6}$ & $<0.03$ & $0.06-0.15^{7}$ & 0.20 & $0.07-0.55^{7}$ & ND & $\mathrm{ND}^{7}$ & ND & \\
\hline Occipital lobe ${ }^{6}$ & $<0.03$ & $0.14 \cdot 0.17^{7}$ & 0.74 & $0.08-0.41^{7}$ & ND & $\mathrm{ND}^{7}$ & ND & \\
\hline Liver $^{6}$ & 0.04 & $0.06-0.54^{7}$ & 0.06 & $0.03-0.13^{7}$ & ND & $\mathrm{ND}^{7}$ & 0.21 & \\
\hline
\end{tabular}

${ }^{1} \mathrm{P}$ : patient: $\mathrm{C}$ : control; ND: not detected.

${ }^{2} \mathrm{Micromoles}$ per $\mathrm{dl}$.

${ }^{3}$ Mean \pm SD of 10 control subjects.

${ }^{4}$ Micromoles per $24 \mathrm{hr}$.

${ }^{5}$ Data from Gerritsen and Waisman (7).

${ }^{6}$ Micromoles per $\mathrm{g}$.

${ }^{7}$ Data from Gerritsen and Waisman (8)

Table 2. Enzyme activities in tissues

\begin{tabular}{|c|c|c|c|}
\hline Subject & $\begin{array}{l}\text { Cystathionine- } \beta- \\
\text { synthase }^{1}\end{array}$ & $\begin{array}{c}N^{5} \text {-Methyltet rahydrofolate } \\
\text { methyltransferase }\end{array}$ & $\begin{array}{l}5,10-\mathrm{Mcthylenc}- \\
\text { tetrahydrofolate } \\
\text { reductase }^{3}\end{array}$ \\
\hline \multicolumn{4}{|l|}{ Patient } \\
\hline Skin fibroblast & 20.96 & 2.17 & 0.53 \\
\hline Liver & 84.80 & 1.19 & 0.00 \\
\hline Brain & 51.80 & 1.05 & 0.59 \\
\hline Skin fibroblast & 34.24 & 2.70 & 5.14 \\
\hline Liver & 189.60 & 1.83 & 13.80 \\
\hline Brain & $22.00^{4}$ & & \\
\hline
\end{tabular}

${ }^{1}$ Nanomoles of cystathionine formed per $135 \mathrm{~min}$ per mg protein.

${ }^{2}$ Nanomoles of methionine formed per hr per mg protein.

${ }^{3}$ Nanomoles of formaldehyde formed per hr per mg protein.

${ }^{4}$ Data from Mudd (21) 
concentrations of methionine. cystathionine, homocystine, and cystine in plasma, urine, and tissues.

It is seen that homocrstine was detected in the plasma and urine In the brain and the liver, methionine concentrations were decreased but cystathionine was detected in normal concentrations.

Tissue activity of cystathionine- $\beta$-sinthase, $N^{5}$-methyltetrahydrofolate homocystine methyltransferase, and 5,10-methylenetetrahydrofolate reductase is shown in Table 2. The validity of these enzyme studies in the postmortem tisses was confirmed by enzyme assays with cultured skin fibroblasts showing a deficiency of 5,10-methylenetet rahydrofolate reductase (32).

\section{GROSS PATHOIOGY}

The body was that of a fair-haired female, with normal height and body weight. Mild pectus cxcavatum and genu valgum were present. There was widespread thrombosis involving the superior saggital sinus, lateral sinuses, their tributaries. and the pulmonary artery and its branches. Multiple infarets were found in the lungs. All the internal organs were of normal size and weight except for the brain which was soft and weighed $940 \mathrm{~g}$ (average normal weight: $1.280 \mathrm{~g}$ ).

\section{LIGHT MII ROSCOPY}

The liver showed fatty changes, extending from the eenter of the lobules to the portal triads. Occasionally, fat cysts were observed. There were no Mallory"s hyaline bodies. The central veins and sinusoids were dilated and their walls contained increased fibrocollagenous tissues. In the portal triads, there were mild to moderate fibrosis and thickened arterioles with intimal hyperplasia. Bile ductules and portal venules were normal. A moderate increase of iron was present in the hepatocytes.

In the spleen, there was sinusoidal congestion and an increased amount of iron. The sphenic arteries showed hyalinization and contained prominent endothelial cells.

Multiple areas of recent infarction were found in the lungs Recent thrombi were observed in the pulmonary arterioles and capillaries.

The thymus contained a well preserved lymphoid population hut epithelial cells were scanty and Hassall's corpuscles were indistinct.

Focal lesions were observed in the aortic wall. There was a moderate degree of intimal hyperplasia associated with regional areas showing sloughing of endothelium. The media showed focal fragmentation and disruption of the elastic lamellate (Fig. 1). the adventitia showed minimal fibrosis, and the lasa vasorum penetrated deeply into the media of the aorta. Focal fragmentation of the elastic lamellac was also found in the iliac and mesenteric arteries. Arterioles in the brain and skeletal muscles showed thickened walls with fibrosis and intimal hyperplasia with swollen endothelial celts.

In the cerebral cortex the major abnormality was in the white matter. consisting of patchy, incomplete perivascular and confluent demyelination with moderate astrocytosis (Fig. 2). There was a paucity of microglial elements. The oligodendrocytes were unremarkable. Cerehral vessels in the deep cortex showed prominent endothelial cells and thick hyalinized walls (Fig. 3), sometimes resembling fibrinoid necrosis. A few of the vessels were thrombosed and were surrounded by a widened perivascular space. Demyelination was out of proportion to the vascular changes. Surprisingly, the vessels in areas where mvelination wals preserved were cuffed by microglial cells and lymphocytes. whereas dempelinated areas contained vessels devoid ol microglial elements. The compound granular corpuscles were found in small numbers. In the gray matter, there were ischemic changes in the form of neuronal loss in the second and third layers with focial areas showing shrunken cells and basophilia. The thalamus and globus

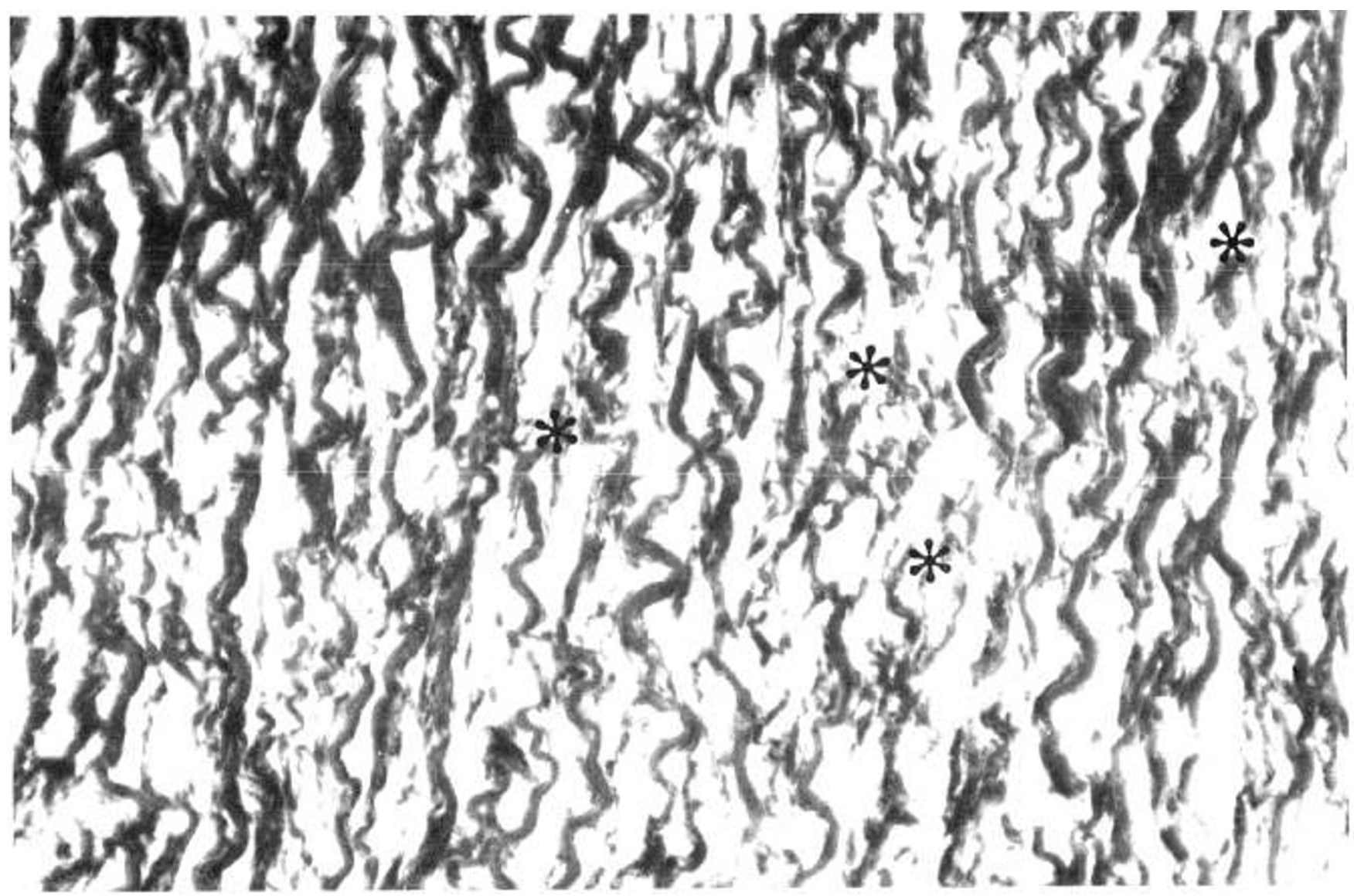

Fig. 1. Photomicrograph of thoracic aorta ( $\times$ 320; clastica) showing focal fragmentation of elastic lamellae $\left(^{*}\right)$. 


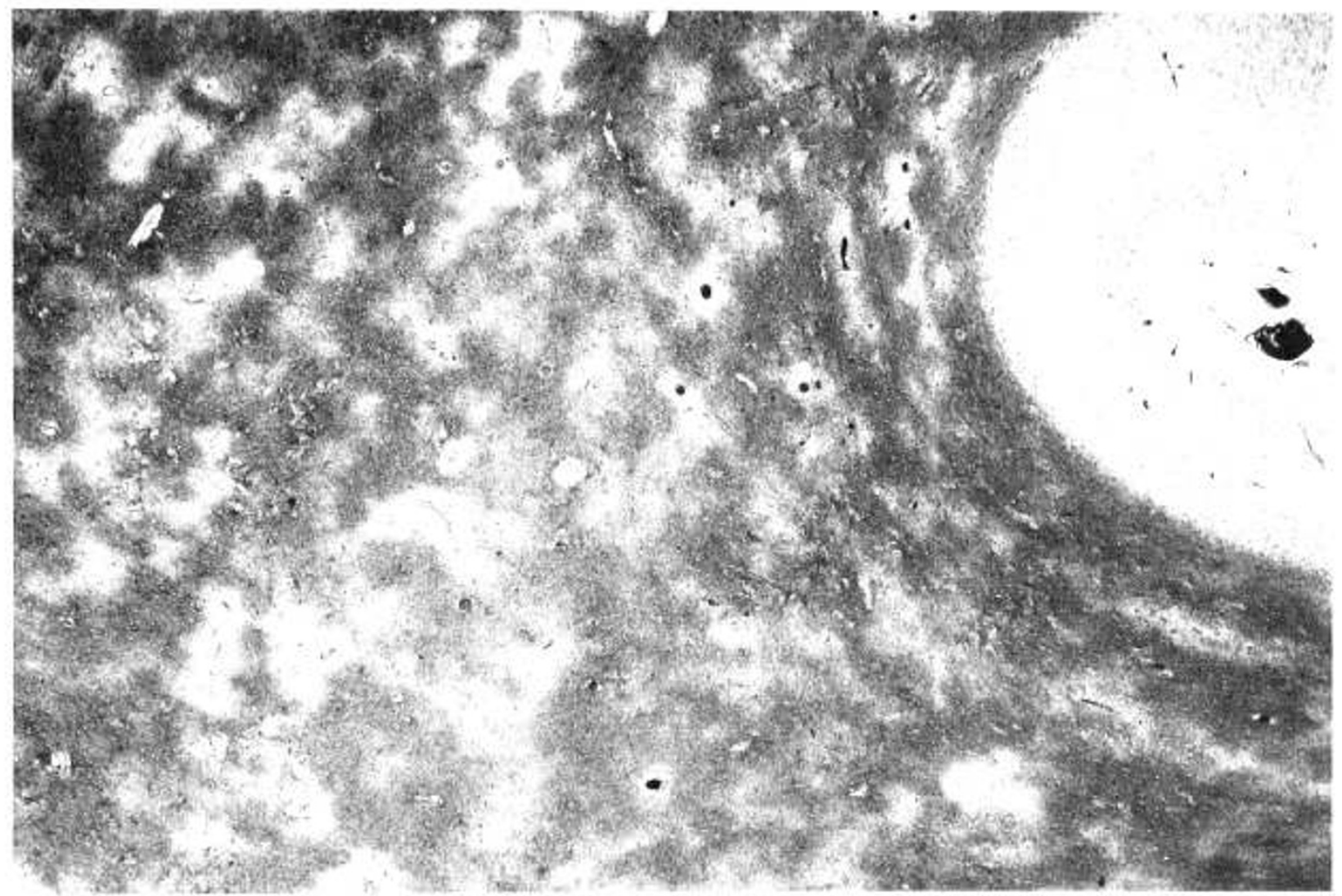

Fig. 2. Cerebral cortex ( $\times 20$; Weil) showing multiple foci of demyelination and thrombi in blood vessels.

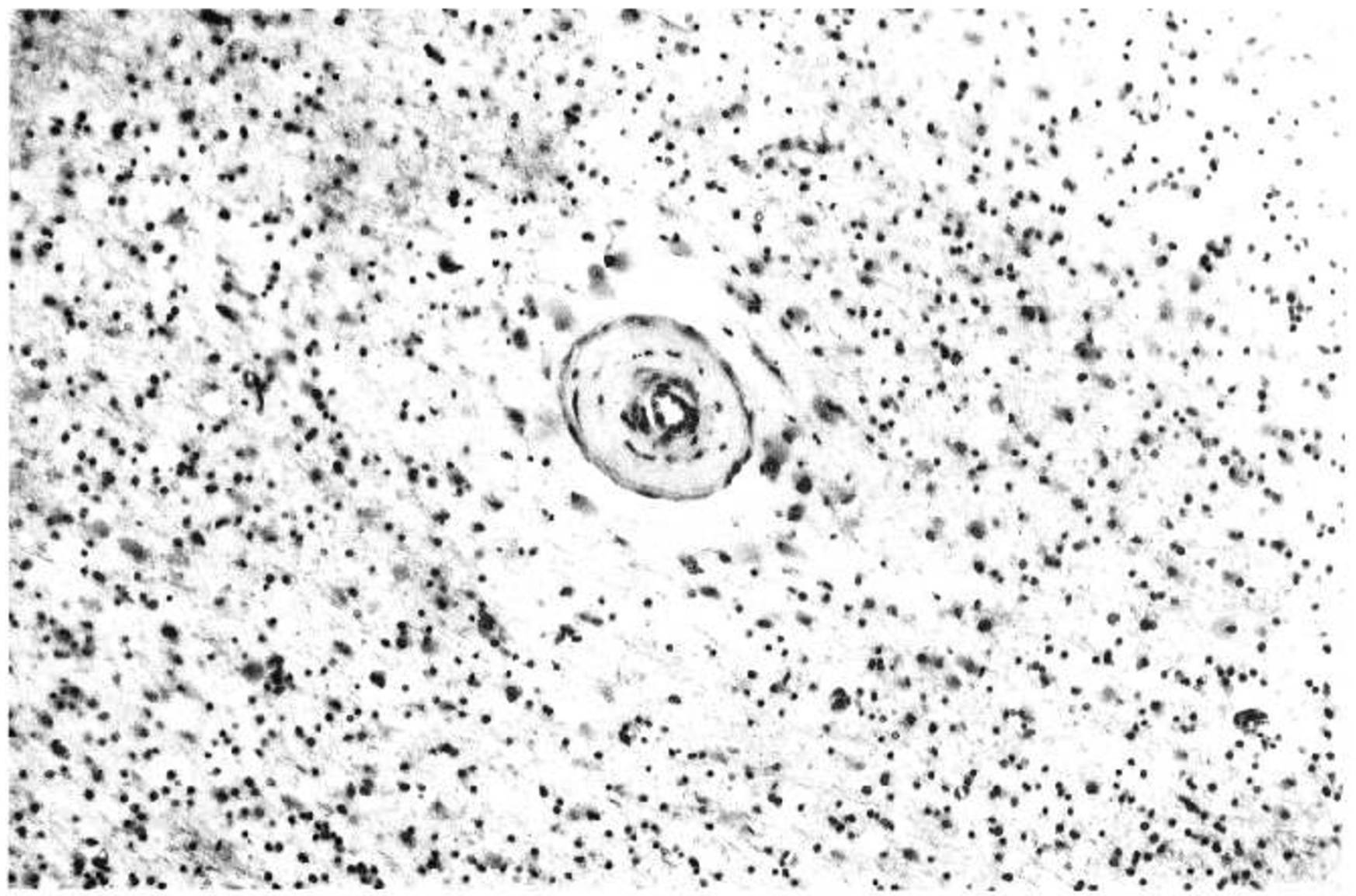

Fig. 3. Photomicrograph of deep cortex $(x$ 200; Klüver $)$ showing an arteriole with hyalinized wall and narrow lumen, enlargement of the perivascular space and the surrounding astrocytes. 


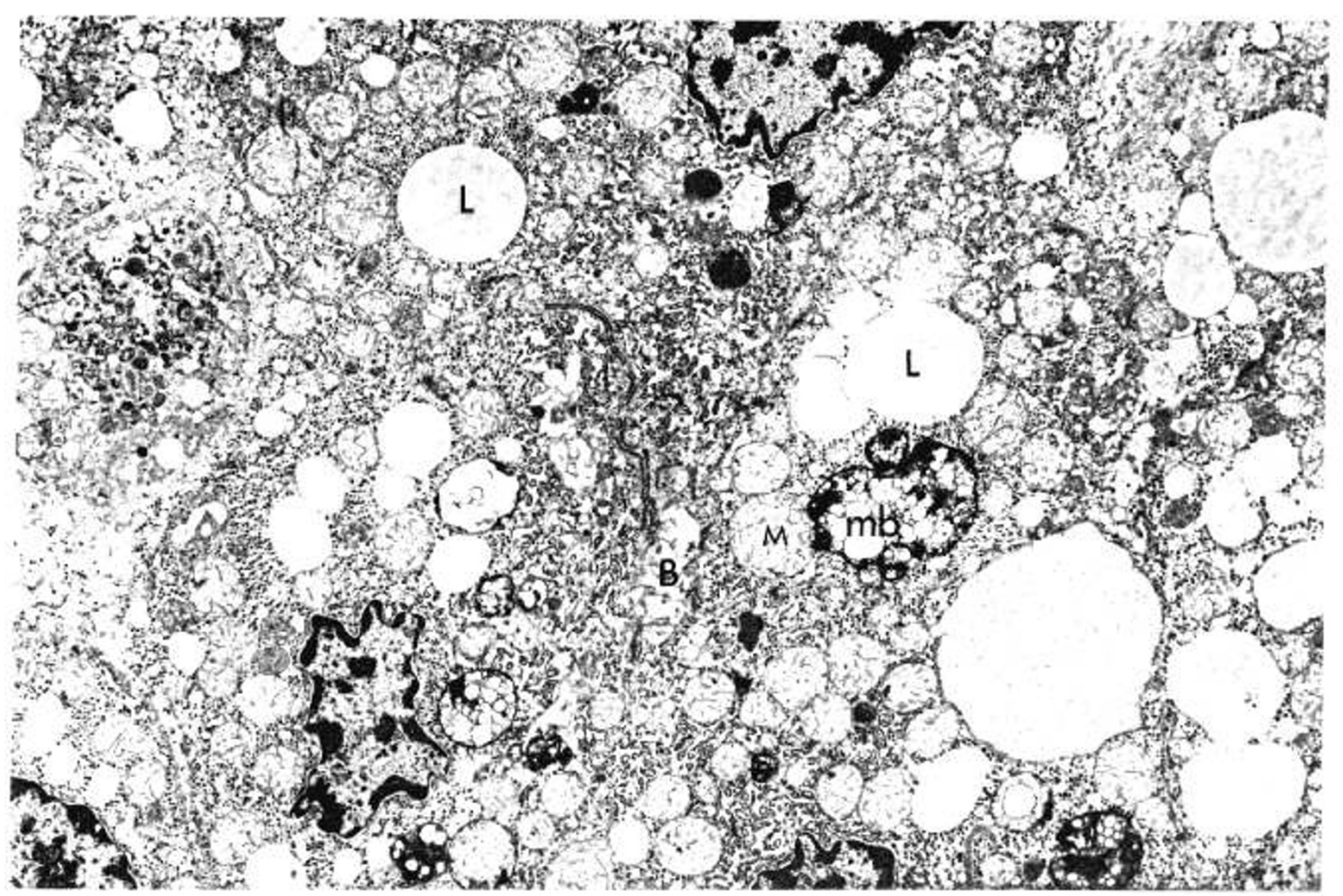

Fig. 4. Electron micrograph of hepatocytes $(x \quad 6,500)$ showing an increased amount of lipid bodies $(L)$, multivesicular bodies $(m b)$, glycogen. rough endoplasmic reticulum, mitochondria $(M)$, and bile cancaliculus $(B)$.

pallidus were normal but the pons and medulla showed focal demyelination in the corticospinal tracts with minimal gliosis. In the cerebellum the deep white matter showed similar although less marked changes than in the cerebral cortex.

\section{ELECTRON MICROSCOPY}

In the liver (Fig. 4), the borders of the hepatocytes were well demarcated. Numerous low density lipid droplets measuring $2 \div 5$ $\mu \mathrm{m}$ in diameter were observed. Peculiar membrane-hound multivesicular bodies with variable matrical density material measuring $0.1-0.4 \mu \mathrm{m}$ in diameter were found. These bodies were close io the lysosomes and were seen within the phagosomes. In other areas, electron-dense bodies resembling ferritin or lipofuchsin pigments were also seen. A few mitochondria showed finger-like projections, whereas others were bizarrely shaped. Giant mitochondria were also observed, but their cristae per unit size were approximately normai ( $\Gamma$ ig. 5). Numerous myclin figures wero seen in the vicinity of degenerating mitochondria and liposomes (Fig. 6). Rough endoplasmic reticulum and glycogen granules were found in abundance. The smooth endoplasmic reticulum was not prominent. There were normal amounts of lysosomes and the nuclei were normal. Focal increase of pericellular collagen was observed. The space of Disse contained swollen microvilli, occasional mitochondria, multivesicular bodies, and lipid droplets. The walls of the central veins showed marked increase in collagen. Mild reactive changes in Kupffer cells were observed. Bile canaliculi were normal.

In the aorta, mild hypertrophy of the remaining endothelial cells was observed. The subendothelial space was increased and was occupied by an increased amount of collagen. The media showed fragmentation and disruption of the elastic lamellae which contained electron-dense reticulate fibers (Fig. 7). The interlamellar space was increased and was occupied by collagen and moderately electron-dense amorphous material. Smooth muscle cells in the media were shrunken and were irregularly formed. Only peripheral attachment devices or intracytoplasmic myofilamentous condensations were demonstrable. In contrast to the smooth muscles of normal aorta, individual myofilaments were seen with difficulty. The abnormal smooth muscle cells showed a slight increase in electron density. Glycogen granules and rough endoplasmic reticulum were slightly reduced. Nuclei were indented but were otherwise normal. Similar changes were observed in samples obtained from the iliac and mesenteric arteries.

Skeletal muscles showed focal fragmentation. disruption. and smearing of the $Z$ discs (Fig. 8). Oblong rods measuring 0.10 .2 $\mu \mathrm{m}$ by $0.20 .4 \mu \mathrm{m}$ were found. In areas where $Z$ dise changes were observe.1, myofilaments and the A. H, and I bands were disorganized. Lysosomes, glycogen, nuclei, and sarcolemmal were normal. The endothelial cells of muscular arterioles showed minimal injury in the form of dilation and hypertrophy of the endoplasmic reticulum and an increase of ribosomes and lysosomal bodies, as well as swelling of the mitochondria. Myclin figures were also found. The nuclei were normal. The basal lamina showed an increase of collagen but the lining smooth muscle cells were mostly normal.

In the brain, the changes observed in the neurons of the cerebral cortex and in the Purkinje cells of the cerebellar cortex were similar. Nissl bodies were disorganized; the rough endoplasmic reticular cisterns were in disarray: and ribosomes and glycogen granules were markedly increased (Fig. 9). Occasional int racytoplasmic filamentous or crystalline and Hirano bodies were found in the Purkinje cells and cortical neurons, respectively (Figs. 9, 10). In addition, lamellar bodies and relatively electron-dense proteinaceous deposits in the vicinity of cisterns of the Purkinje cells were observed (Fig. 11). The macroglial elements (astrocytes and oligodendrocytes) showed reactive changes in the form of increased intracytoplasmic fibrils, glycogen particles, and electrondense bodies. Their cisterns were also in disarray. The neuropile of the cortex, pons, and medulla showed striking and similar changes. 


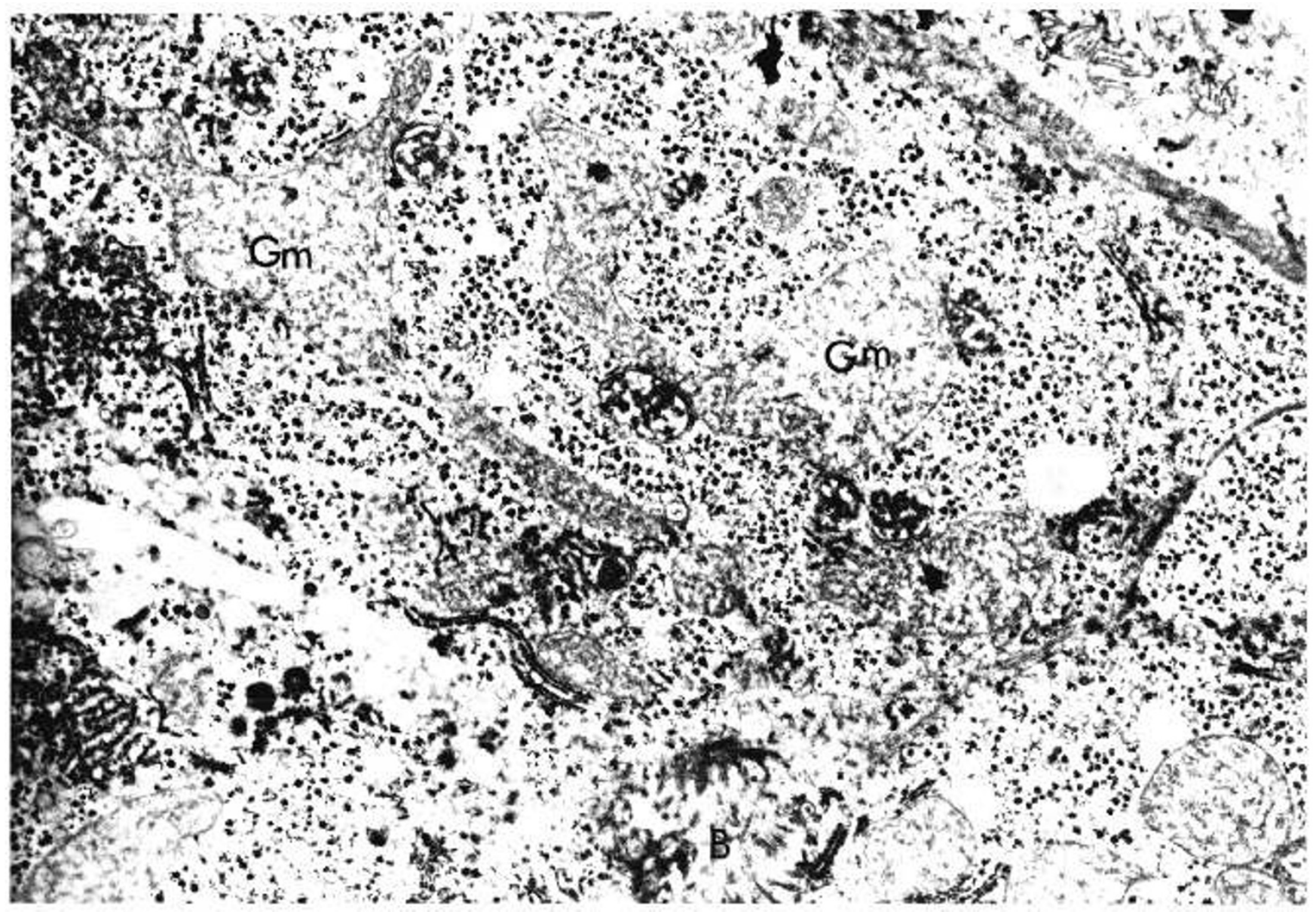

Fig. 5. Electron micrograph of hepatocytes $(\times 10,000)$ showing bizarre, giant mitochondria $(G m)$ and bile canaliculus $(B)$.

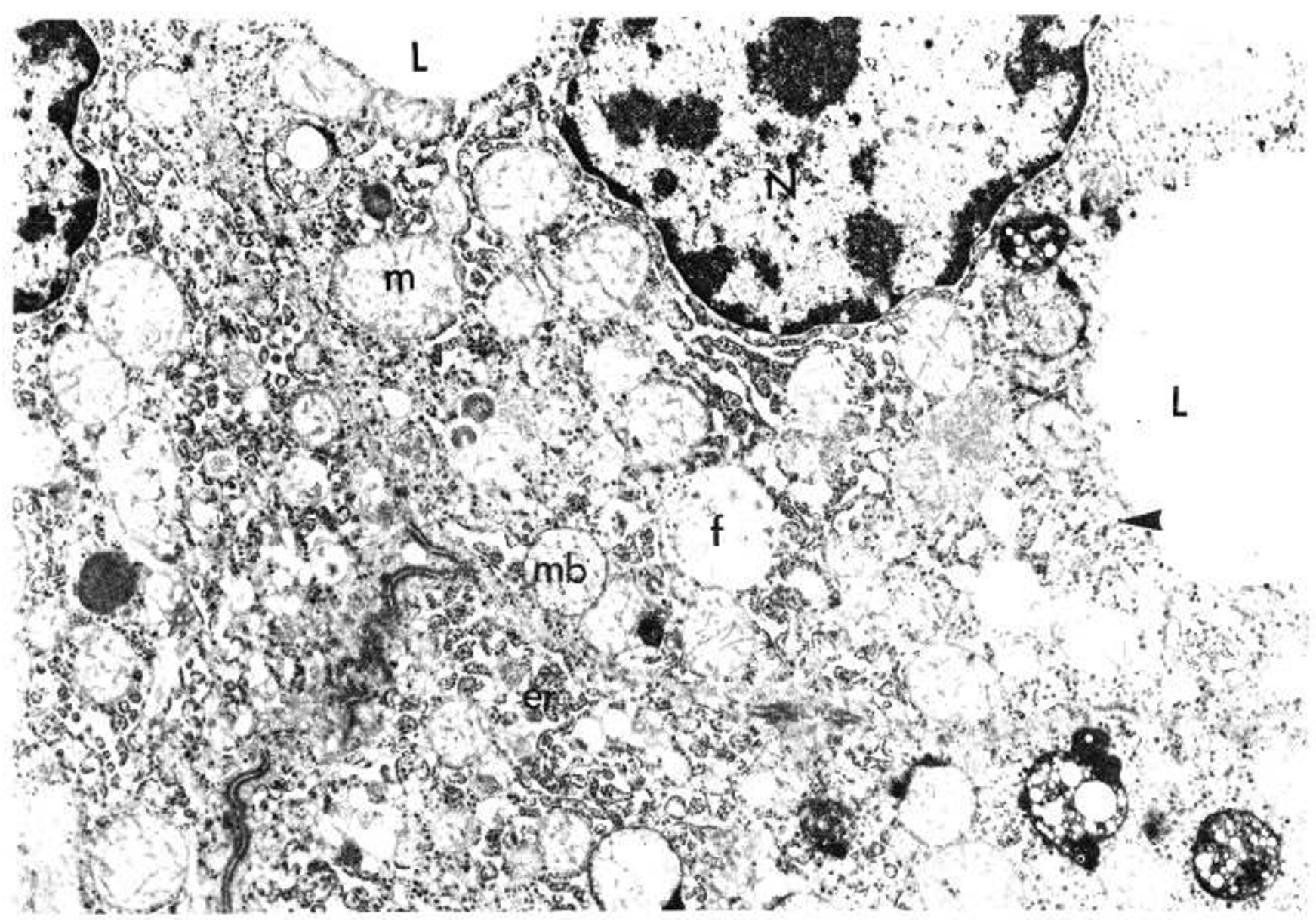

Fig. 6. Electron micrograph of hepatocytes $(\times 10,500)$ showing an increased amount of multivesicular bodies $(m b)$, myelin figures $(f)$, lipid bodies $(L)$, dilated rough endoplasmic reticulum $(e r)$, glycogen (arrow), mitochondria $(m)$, and nucleus $(N)$. 


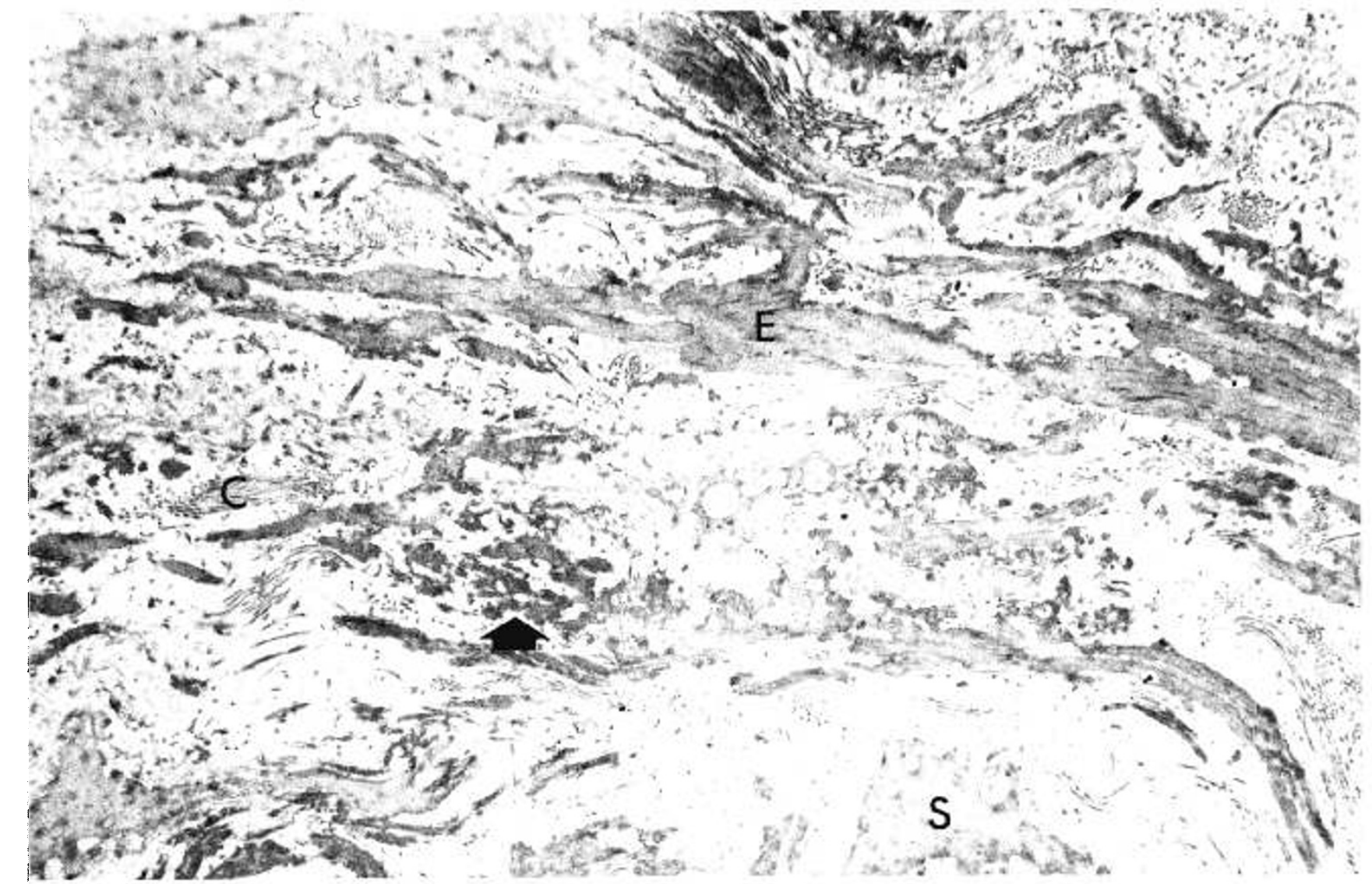

Fig. 7. Electron micrograph of medial portion of the thoracic aorta $(\times 6,500)$ showing thin and fragmented elastic lamellae $(E)$, irregularly formed smooth muscle $(S)$, electron-dense amorphous deposits (arrow) in the loose interlamellar space, and collagen $(C)$.

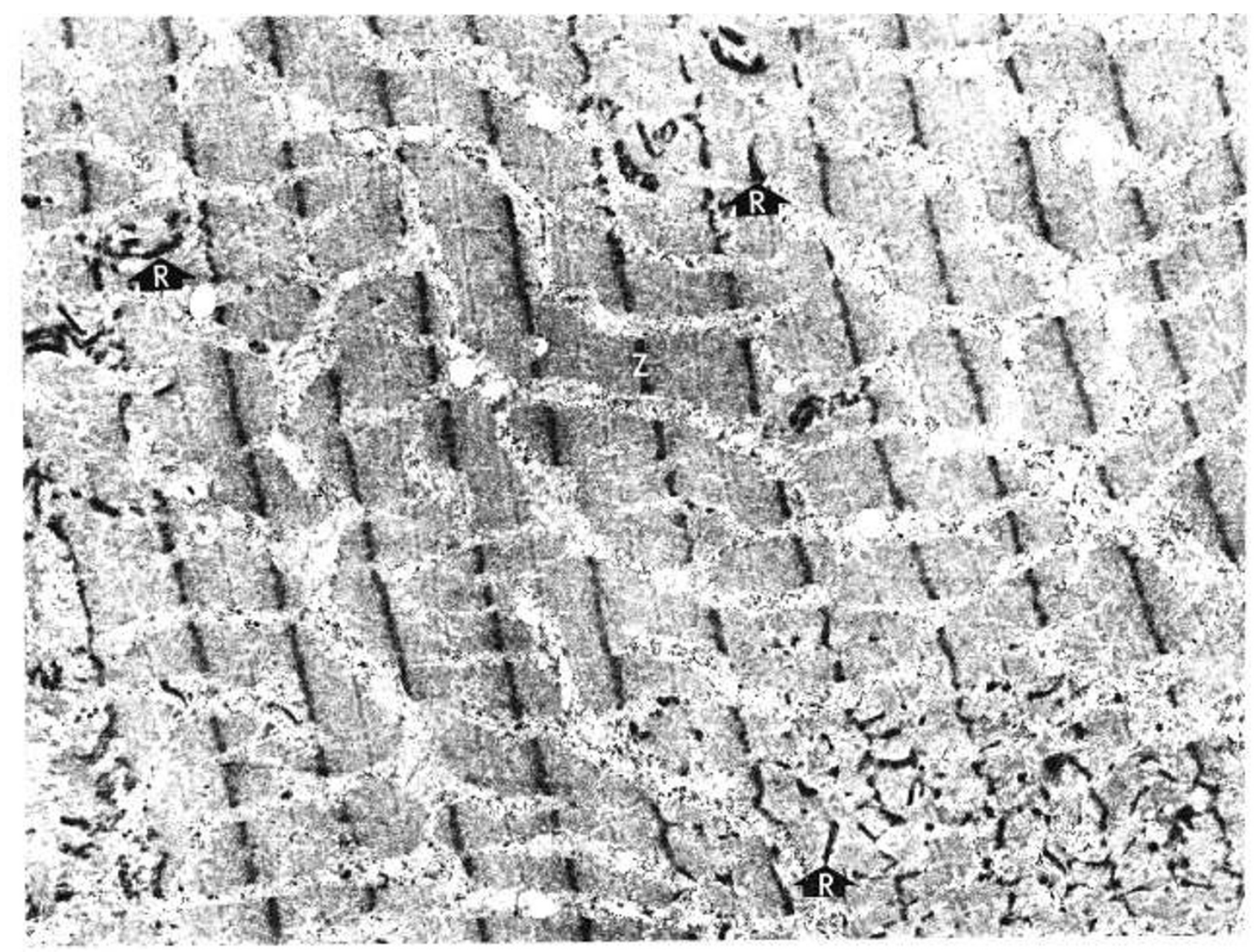

Fig. 8. Electron micrograph of skeletal muscle $(\times 7,500)$ showing focal areas of fragmentation and disruption in the $Z$ lines $(Z)$ and rod $(R)$ formation. 


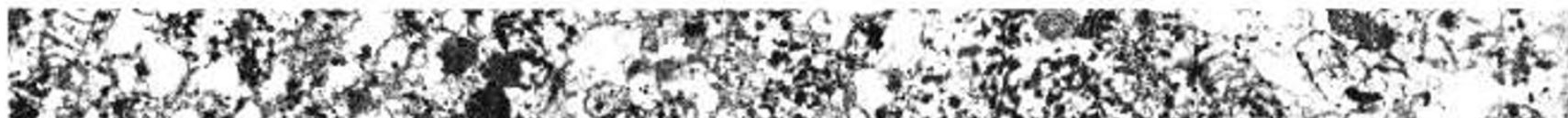

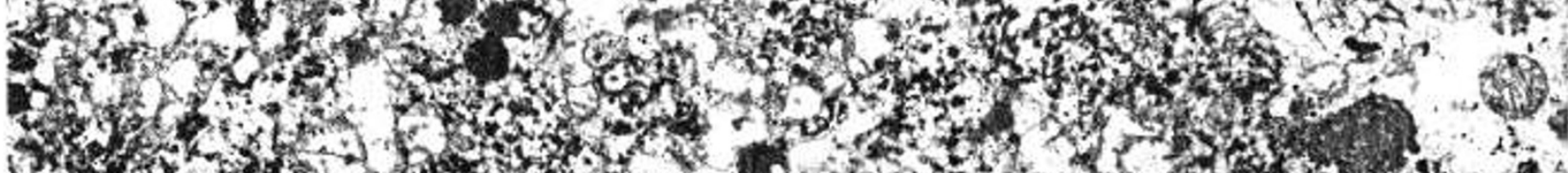

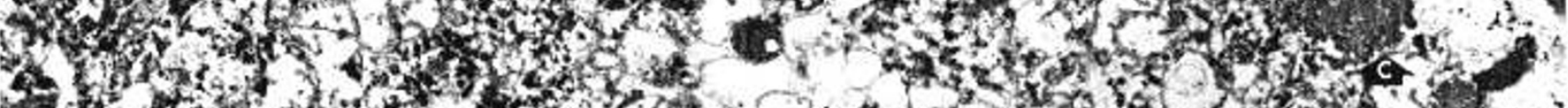

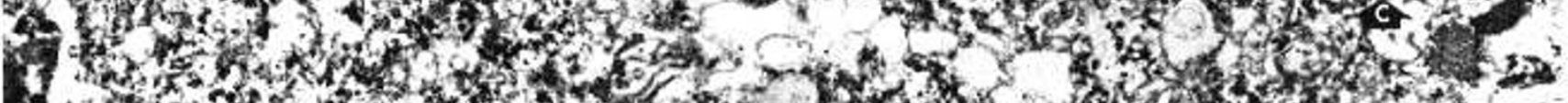

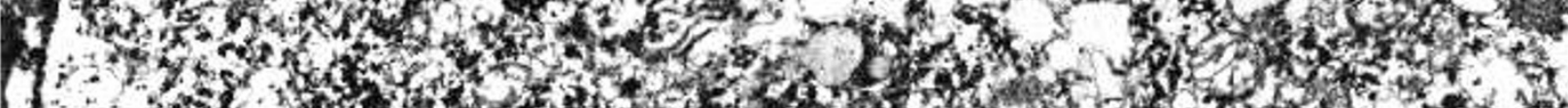
6. 3 . 7.

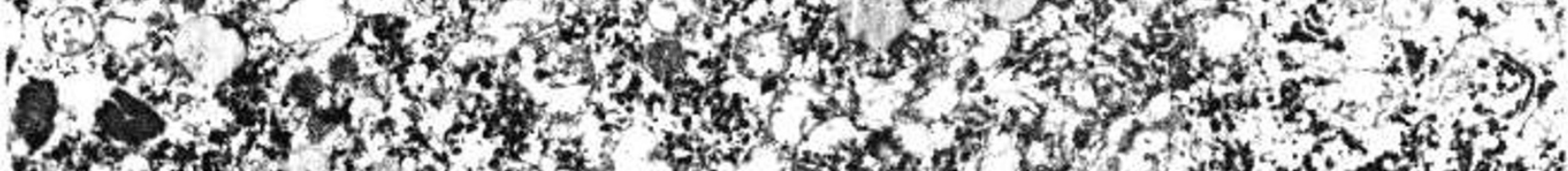

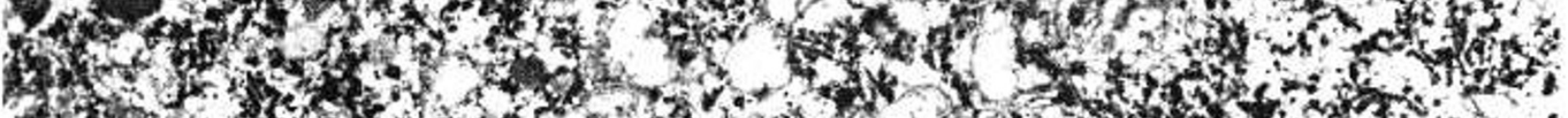

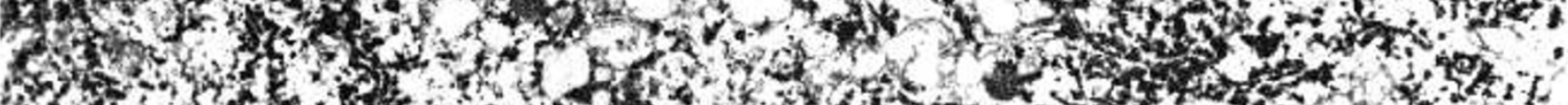

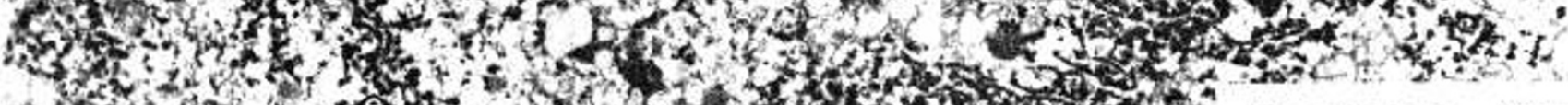

(1)

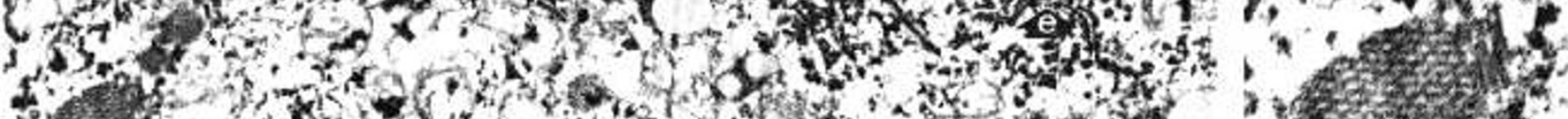

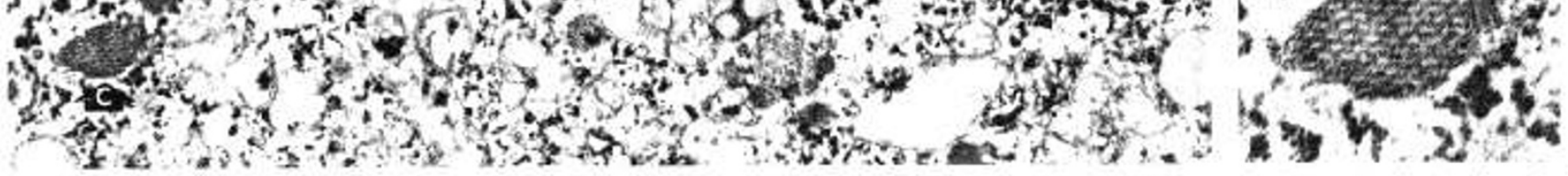

Fig. 9. Electron micrograph of a Purkinje cell in the cerebellar cortex $(x \quad 10,500)$ showing the disarray of the rough cisternai endopiasmic reticuilum $(e)$, crystalline bodies $(c)$, and a relative increase of ribosomes and glycogen. Inset showing a crystalline body at a higher magnification.

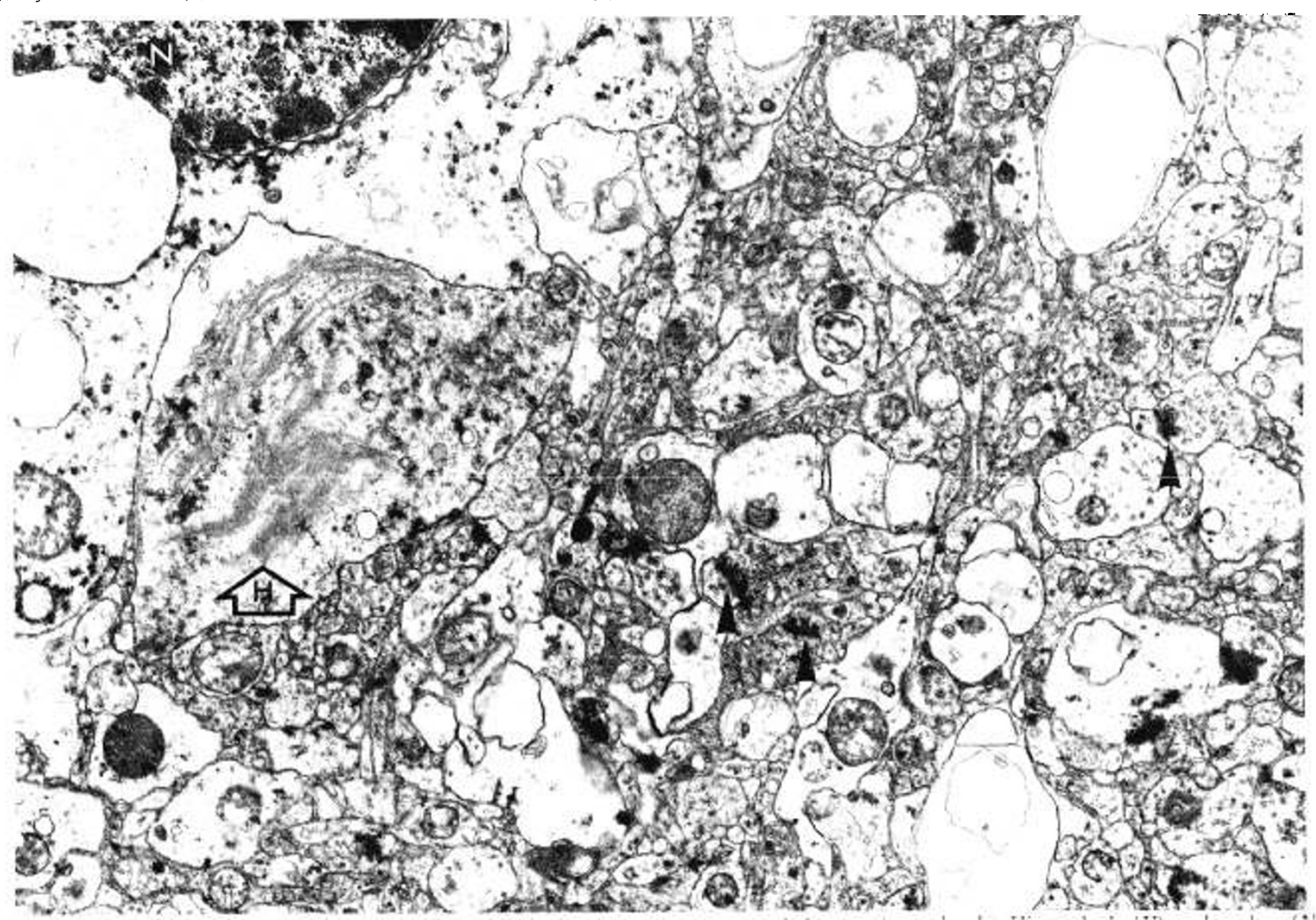

Fig. 10 Electron micrograph of cerebral cortex $(\times 9,050)$ showing a neuron, synaptic buttons (arrowheads), Hirano body $(\hat{H})$, and nucleus $(\hat{N})$. 


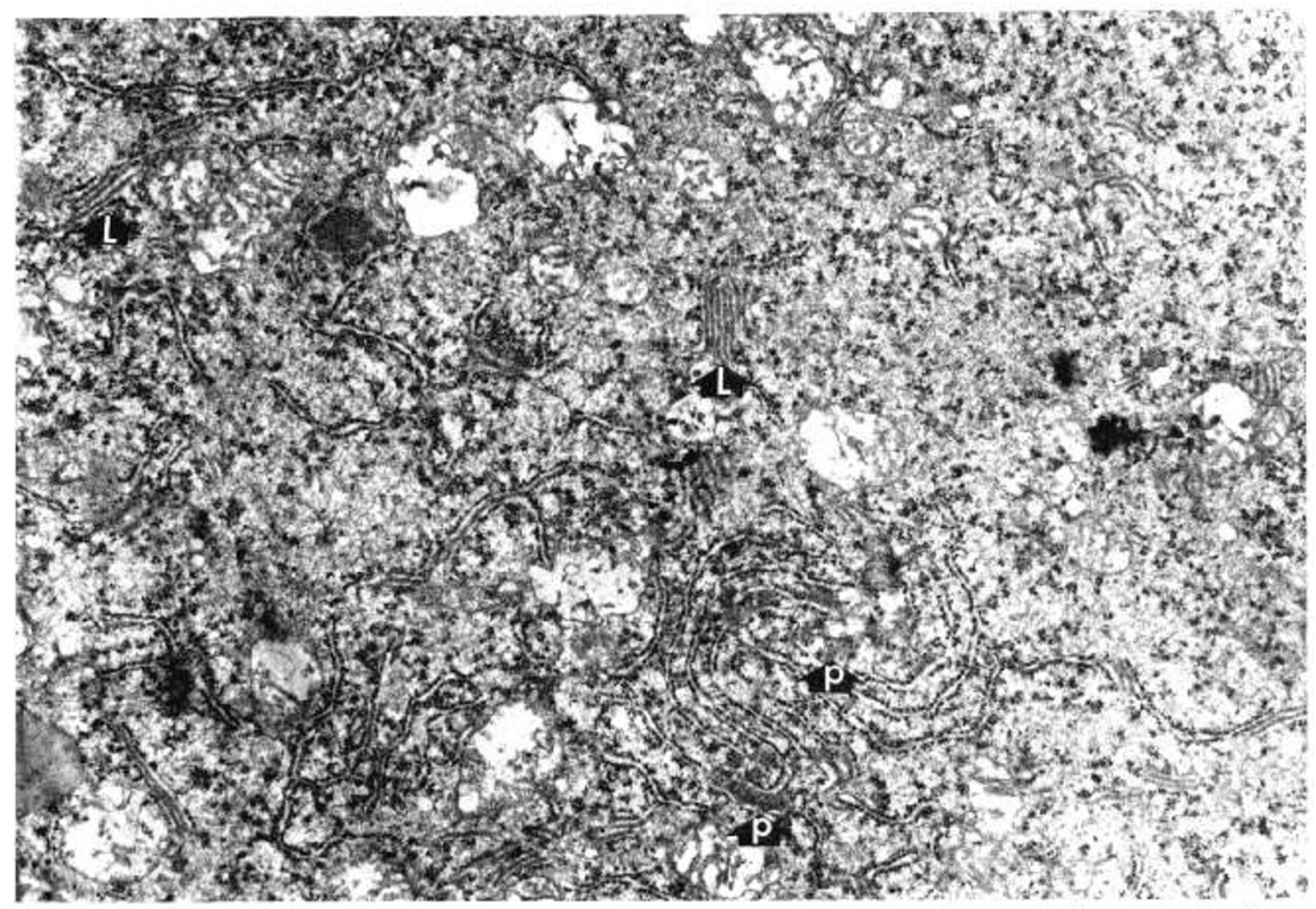
L)

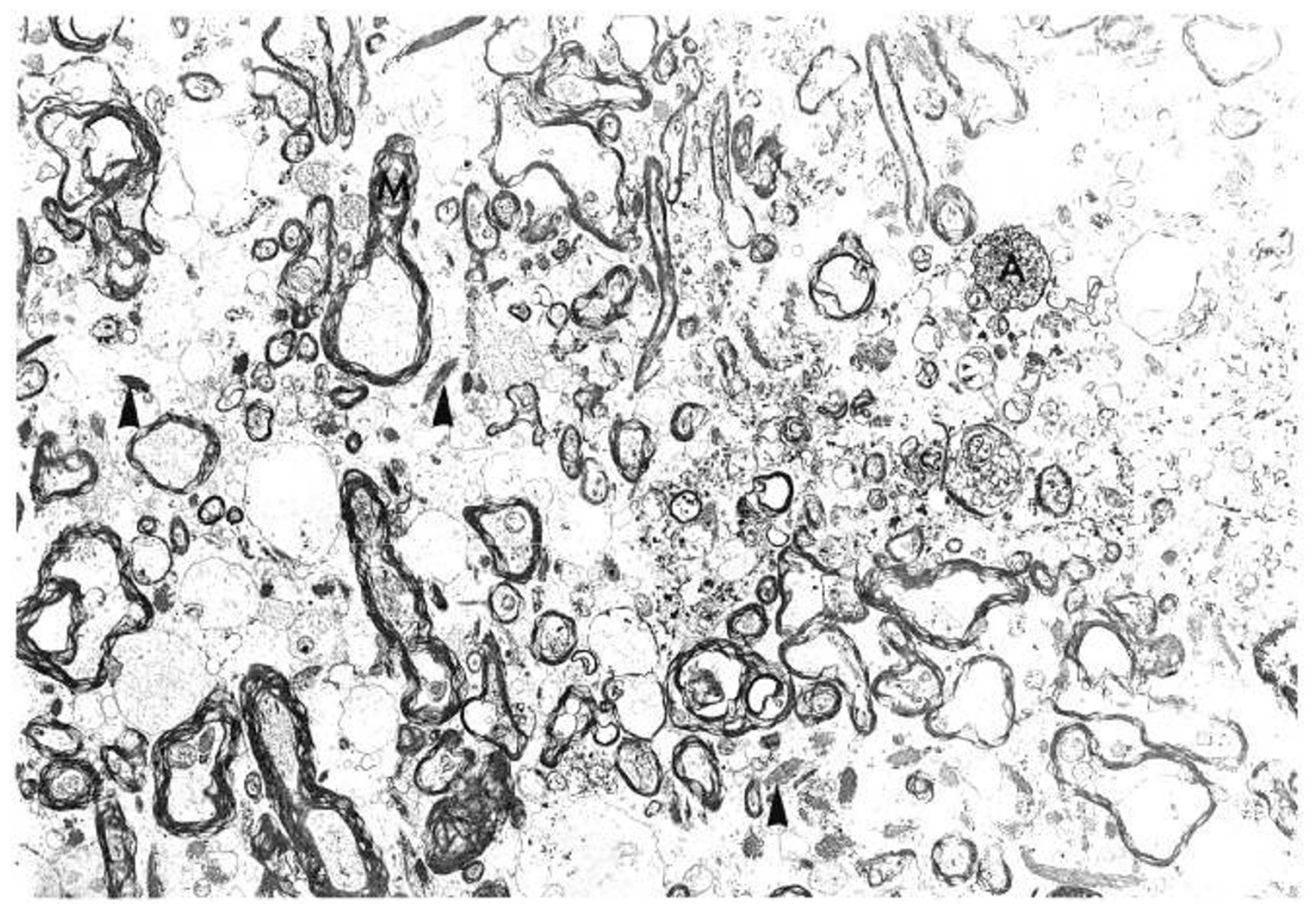

Fig. 12. Electron micrograph of neuropile of cortex $(\times 4,000)$ showing demyelination of myelin sheath $(M)$, filamentous bodies (arrowheads). vesiculated bodies in completely demyelinated axon $(A)$, and a paucity of synaptic buttons. 
There were areas of moderate demyelination with focal wrinkling and dissolution of the periodicity of the myelin sheath (Fig. 12) Some of the demyelinated axons contained only a thin rim of myelin sheath. In some areas, the axoplasm was displaced outwards and the periaxonal space was swollen (Fig. 13). In these axons, there was an increase of electron density and focal disruption of the neurotubules. Some areas, especially in the medulla, where complete disappearance of axons occurred, were filled with vesiculated bodies. degenerated mitochondria, and myelin figures. Numerous filamentous bodies measuring 0.20 .7 $\mu \mathrm{m}$ in size were observed. In the neuropile of the cortex, there were areas where synaptic buttons were few whereas, in other areas, they were found in normal numbers (Figs. 10, 12).

The kidneys showed minimal abnormalities. The glomeruli were generally shrunken with partially compressed capillary spaces. The basement membranes showed mild but diffuse thickening of the lamina densa: and the lamina rarae were indistinct. Wrinkled basement membranes were found in many areas, especially those near the mesangial zones. Wrinkling was not associated with splitting. There was a slight increase of the mesangial matrix. Epithelial cells and endothelial cells were swollen and the epithelial cells showed prominent primary trabecular processes which at tached directly to the basement membranes more frequently than usual.

\section{DISCUSSION}

Morphologic (1, 2, 9) and electron microscopic studies $(6,18$ $25,27)$ in patients with cystathionine- $\beta$-synthase deficiency have been reported by various authors. In addition, morphologic studies in patients with $N^{5}$-methyltetrahydrofolate homocystine methyltransferase deficiency have also been described (18). However, this communication records the first detailed morphologic and electron microscopic description in a patient with 5,10-methylenetetrahydrofolate reductase deficiency. The lesions observed in the latter share many common features with patients suffering from other forms of homocystinuria, suggesting the presence of a common factor in the pathogenesis of many of the structural abnormalities.

The predominant abnormalities were found in the arterial bed. Widespread vascular injury and thrombosis were observed in our patient as in patients with other types of homocystinuria. It is of interest that similar lesions have been observed in a metabolic defect of vitamin $B_{12}(3)$. The latter is converted to methyl- $B_{12}$, the cofactor of $N^{5}$-methyltetrahydrofolate homocystine methyltransferase.

Two hypotheses have been postulated to account for the thrombotic tendency in patients with homocystinuria. In 1964. McDonald et al. (20) suggested that homocystine and other sulfur-containing amino acids, such as methionine, caused increased "platelet stickiness," and that this might be the cause of many vascular accidents in homocytinuric patients. However. other investigators were unable to substantiate their findings (5), and platelet function studies in our patient revealed no abnormality (32). In addition, the changes in the vascular wall observed in patients with homocystinuria are not generally found in vessels with recent or old thrombi secondary to hypercoagulability of the serum or platelet dysfunction.

A second hypothesis to account for the thrombotic tendency is the occurrence of an initial vascular injury. In our patient, as well as in patients with other forms of homocystinuria, widespread endothelial and subendothelial changes, involving the smooth muscles and elastic tissues, were observed. These changes often occurred without thrombosis, suggesting that any thrombosis is secondary to the preceding vascular lesions. It seems that homo-

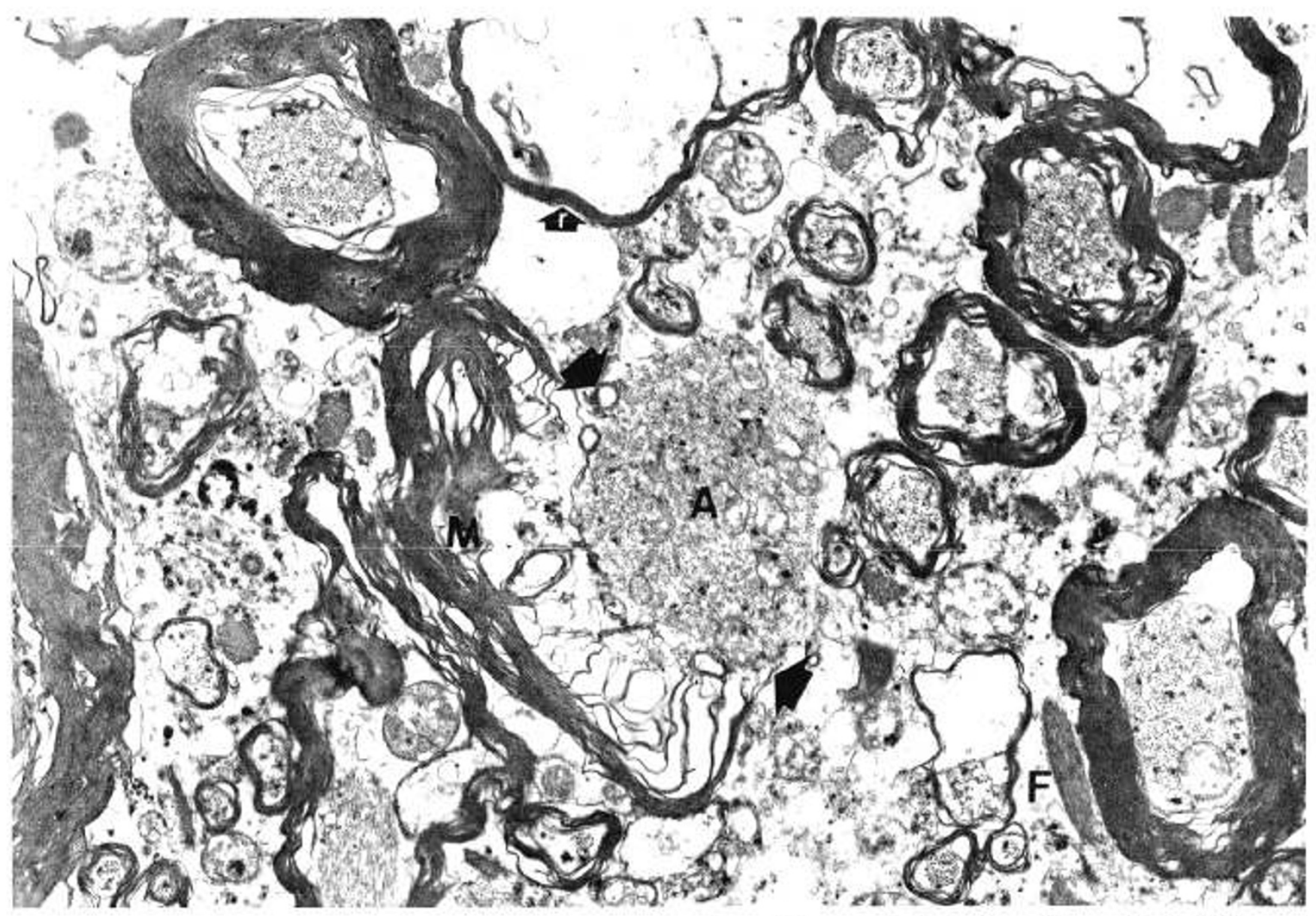

Fig. 13. Electron micrograph of medulla $(x \quad 10,500)$ showing demyelinated axon $(A)$ completely displaced out of the myelin sheath (iarge arrows) and enlargement of periaxonal space, wrinkling and loss of periodicity of myelin sheath $(M)$, the thin rim of a remaining myelin sheath $(r)$, and filamentous body $(F)$. 
cystine is the most likely "toxic agent" to the vasculature, as it is detected in the plasma in all forms of homocystinuria and as methionine is normal or subnormal in deficiency of $N^{5}$-methyltet rahydrofolate homocystine methyltransferase and 5,10methylenetetrahydrofolate reductase. The observations in experimental homocystinuria in baboons (11) provide further support to this hypothesis. However, it is not known if the initial injury is in the endothelium, resulting in subsequent damages in the elastic tissues and smooth muscles, or if the initial injury is in the connective tissues, leading to subsequent changes in the endothe lium. The observations that the collagen obtained from homocystinuric patients (12) and that proteoglycans synthesized by skin fibroblasts from these patients (19) were abnormal tend to support the latter possibility.

The thrombosis in the dural sinuses and cerebral veins was neither accompanied by cerebral infarction nor significant changes in the vessel wall, suggesting a recent and terminal event. The reason for the lack of damage in the venous walls is unexplained.

The conspicuous demyelination observed by light as well as by electron microscopy and the disorganization of cisternal array in the cells of the central nervous system may be due to ischemia and thrombosis secondary to the vascular disease. However, the demyelination, which is perivascular to some extent, is out of proportion to the vascular lesions, thus suggesting the effect of a diffusible toxic agent. The presence of crystalline and lamellar bodies in the Purkinje cells and Hirano bodies in the cortical neurons possibly reflects disordered protein metabolism of the cells. These have been seen in amyotrophic lateral sclerosis, Parkinsonism-dementia complex, and Pick's disease $(13,15,26)$. The presence of minimal gliosis also suggests a sustained toxic injury rather than the sole responsibility of the vascular lesions. It seems, therefore, that ischemia and vascular thrombosis are not the only causative factors in the structural abnormalities in the brain.

The nature of the abnormalities in the hepatocytes remains speculative. Giant mitochondria, abnormal changes in the rough endoplasmic reticulum, myelin figures, and excessive lipid droplets can be induced by chemical agents such as alcohol, phenobarbital, and chlorpromazine (29). Megamitochondria have also been observed in obstructive jaundice, Rotor syndrome, and riboflavin deficiency (28). Luck has shown that in choline-dependent neurospora, deprivation of choline results in enlargement of the mitochondria (17). It may be suggested that deficiency of methyl donors such as choline, methionine, or methyltetrahydrofolate may be responsible for the abnormalities in the mitochondria and the fatty changes. However, similar changes are observed in cystathionine- $\beta$-synthase deficiency without a lack of methyl donors. The multivesicular bodies, similar to those observed in Wilson's disease and alcoholic cirrhosis (29), and the autophagic vacuoles suggest a rapid turnover of the organelle. The remarkably dilated central veins and increase of perivascular collagen may be due to intrahepatic congestion secondary to microthrombi formation. In contrast to Gaull and Schaffner's observations on patients with cystathionine- $\beta$-synthase deficiency (6), we did not detect any increase in smooth endoplasmic reticulum in the hepatocytes, thus supporting their contention that the increase in smooth endoplasmic reticulum was probably an expression of high tissue concentrations of methionine.

Fragmentation, disruption, and smearing of the $Z$ discs in skeletal muscles have been observed in various disorders such as myotonic dystrophy, cold injury, and alcoholism (24). These changes in the $Z$ discs and the rod formation are probably nonspecific or ischemic in nature.

The renal abnormalities, however, can best be explained on the basis of renal ischemia.

In conclusion, the similarities of the pathologic abnormalities in this patient to other types of homocystinuria suggest that homocystine is the agent responsible for the widespread lesions in the vasculature, brain, and liver. In addition, ischemia secondary to vascular disease plays a role in some of the pathologic changes, especially in the skeletal muscle and kidney.

\section{SUMMARY}

Morphologic studies on a patient with homocystinuria due to 5,10 -methylenetetrahydrofolate reductase are described.

The arterial lesions were prominent and showed fragmentation of the elastic lamellae. Perivascular demyelination and thrombosis were observed in the brain. Hirano bodies in the cortical neurons and crystalline and lamellar bodies in the Purkinje cells were present. Lipid droplets, giant mitochondria, myelin figures, and membrane-bound multivesicular bodies in the hepatocytes were seen. Fragmentation of the $Z$ discs of striated muscle and wrinkling of the glomerular basement membrane were observed.

The morphologic lesions observed in this patient were, to some extent, similar to those described in patients with homocystinuria with either cystathionine- $\beta$-synthase or $N^{5}$-methyltet rahydrofolate homocystine methyltransferase deficiency. Furthermore, it is suggested that the pathologic changes observed are probably "vasculotoxic" in nature.

\section{REFERENCES AND NOTES}

1. Carson, N. A. J., Dent, C. E., Field, C. M. B., and Gaull, G. E.: Homocystinuria: Clinical and pathological review of ten cases. Pediatrics, 66: 565 (1965).

2. Chow, S. M.. and Waisman, H. A.: Spongy degeneration of the central nervous system. Arch. Pathol., 79: 357 (1965).

3. Dayan, A. D., and Ramsey, R. B.: An inborn error of vitamin $B_{12}$ metabolism associated with cellular deficiency of co-enzyme forms of vitamin. Neurol. Sci. 23: $117(1974)$

4. Freeman, J. M., Finkelstein, J. D., and Mudd, S. H.: Folate-responsive homocystinuria and "schizophrenia": a defect in methylation due to deficient 5 , 10-methylenetetrahydrofolate reductase activity. N. Engl. J. Med., 292: 491 (1975).

5. Gaull, G. E.: The pathogenesis of homocystinuria, Amer. J. Dis. Child., //3: 103 (1967).

6. Gaull, G. E., and Schaffner, F.: Electron microscopic changes in hepatocytes of patients with homocystinuria. Pediat. Res., 5: 23 (1971).

7. Gerritsen, T., and Waisman, H. A.: Homocystinuria, an error in the metabolism of methionine. Pediatrics, 33: 413 (1964).

8. Gerritsen, T., and Waisman, H. A.: Homocystinuria: Absence of cystathionine in the brain. Science, 145: 588 (1964).

9. Gibson, J. B., Carson, N. A. J., and Neill, D. W.: Pathological findings in homocystinuria. J. Clin. Pathol., 17: 427 (1964).

10. Goodman, S. I., Moe, P. G., Hammond, K. B., Mudd, S. H., and Uhlendorf, B. W.: Homocystinuria with methylmalonic aciduria: Two cases in a sibship. Biochem. Med., 4: 500 (1970).

11. Harker, L. A., Slichter, S. J.. Scott, R. C., and Ross, R.: Homocystinemia: Vascular injury and arterial thrombosis. N. Engl. J. Med., 291: 537 (1974).

12. Harris, E. D., and Sjoerdsma, A.: Collagen profile in various clinical conditions, Lancet, ii: 707 (1966)

13. Hirano, A., Dembitzer, H. M., Kurland, L. T., and Zimmerman, H. M.: The line structure of some intraganglionic alterations. J. Neurol. Pathol. and Exp. Neurol., 27: 167 (1968).

14. Hyanek, J., Bremer, H. J., and Slavik, M.: "Homocystinuria" and urinary excretion of $\beta$-amino acids in patients treated with 6 -azauridine. Clin. Chem. Acta, 25: 288 (1969).

15. LeBeaux. Y. J.: Subsurface cisterns and lamellar bodies: Particular forms of the endoplasmic reticulum in the neurons. Z. Zellforsch.. 133: 327 (1972).

16. Levy, H. L., Mudd, S. H., Schulman, J. D., Dreyfus, P. M., and Abeles, R. H.: A derangement in $\mathbf{B}_{12}$ metabolism associated with homocystinemia cystathioninemia, hypomethioninemia and methylmalonic acidura. Amer. J. Med., 48: $390(1970)$

17. Luck. D. J. L.: The influence of precursor pool size on mitochondrial composition in Neurospora crassa. J. Cell Biol., 24: 445 (1965).

18. McCully, K. S.: Vascular pathology of homocystinemia: Implications for the pathogenesis of arteriosclerosis. Amer. J. Pathol., 56: 111 (1969)

19. McCully, K. S.: Importance of homocysteine-induced abnormalities of proteoglycan structure in arteriosclerosis. Amer. J. Pathol., 59: 181 (1970).

20. McDonald, L., Bray, C., Field, C.. Love, F., and Davies, B.: Homocystinuria, thrombosis and the blood-platelets. Lancet, $i: 745$ (1964).

21. Mudd, S. H., Finkelstein, J. D., Irreverre, F., and Laster, L.: Transsulfuration in mammals. J. Biol. Chem., 20: 4382 (1965).

22. Mudd, S. H., Uhlendorf, B. W., Freeman, J. M., Finkelstein, J. D., and Shih, V. E.: Homocystinuria associated with decreased methylene-tetrahydrofolate reductase activity. Biochem. Biophys. Res. Commun., 46: 905 (1972).

23. Mudd, S. H., Uhlendorf, B. W., Hinds, K. R., and Levy, H. L.: Deranged $B_{12}$ metabolism: Studies of fibroblasts grown in tissue culture. Biochem. Med., 4: 215 (1970)

24. Pearson, E. M., and Mostofi, F. K.: The Striated Muscle, p. 144 (The Williams \& Wilkins Co., Baltimore, 1973)

25. Ramsey, M. S., Yanoff, M., and Fine, B. S.: The ocular histopathology of homocystinuria: A light electron microscope study. Amer. J. Ophthalmol., 74: 377 (1972).

26. Schochet, S. S., Lampert, P. W., and Lindenberg. R.: Fine structure of the Pick and Hirano bodies in a case of Pick's disease. Acta Neuropathol., 11: 330 (1968). 
27. Takebayashi, S Grobe, $\mathrm{H}$ von Bassewitz, D. B and Therman, H : Ultrastructural atspects of vessel alterations in homocystinuria. Virchow's Arch. Abr. A Pathol. Anat., 354: 4 (1971).

28. Tandler. B. T., Erlandson, R. A., and Wynder, E. I..: Riboflavin and mouse hepatic cell structure and function. Amer. J. Pathol., 5?:69 (1968)

29. Tanikawa, L.: Ultrastructural Aspects of the Liver and lts Disorders (lgaker Shoin, Ltd. Tokso, 1968)

30. Uhlendorf, B. W., Conerly, E. R., and Mudd, S. H.: Homocystinuria: Studies in tissue culture. Pediat. Res., 7: 645 (1973)

31. Wong, P. W. K.. and Fresco, R.: Tissue cystathionine in mice treated with cysteine and homoserine. Pediat. Res., 6: 172 (1972).

32. Wong, P. W. K. Justice, P.. Weiss. E.. Hruby, M. and Diamond, E. A family with four cases of 5,10 -methylenetetrahydrofolate reductase deficiency. (In preparation.)

33. Wong. P. W. K.. Schware. V.. and Komrower. (i. M.: The biosinthesis of cystathionine in patients with homocystinuria. Pediat. Res.. 2: 149 (1968).

34. The authors would like to thank K. Curley, N. Becker, and K. Jarosius for thei technical assistance and Drs. B. Chomet. Orville T. Bailey, and Mars B. Buschman for their suggestions in the interpretations of brain and liver electron micrographs.

35. This study was supported by Public Health Service Research Grant no. R01 N508532NTN and a grant from the Illinois Department of Mental Health.

36. Requests for reprints should be addressed to: Paul W. K. Wong, M.D. Department of Pediatrics. Presbyterian-St. Luke's Medical Center, Rush Medical School, Chicago. III. 60612 (USA).

37. Accepted for publication December 18, 1975

\title{
Effects of Calcium on Intestinal Mucin: Implications for Cystic Fibrosis
}

\author{
J. F. FORSTNER ${ }^{24}$ AND G. G. FORSTNER \\ Research Institute, The Hospital for Sick Children. Toronto, Ontario, Canada
}

\section{Extract}

A major feature of the disease cystic fibrosis is the excessive concentration of mucus within ducts and glands of mucousproducing organs. Some mucous secretions also show an eleration in calcium concentration. Using purified rat intestinal goblet cell mucin as a model mucin, we have investigated the effect of millimolar additions ( $125 \mathrm{mM}$ ) of $\mathrm{CaCl}_{2}$ on the physical properties of the mucin. Isotonicity of incubation media was preserved in order to mimic in vivo conditions. $\mathrm{CaCl}_{2}(8-15 \mathrm{mM})$ caused a $15-33 \%$ decrease in viscosity, no change in electrophoretic mobility in acrylamide gels, and a $20-30 \%$ decrease in solubility of the mucin. Solubility changes were reversed by the addition of EDTA $(20 \mathrm{mM})$ to incubations. Insolubility was also produced in incubations of mucin with a mixture of soluble intestinal contents ( $\mathrm{NaCl}$ washings). These findings strongly suggest that the mucin became smaller and more dense as calcium was added, a process most probably achieved by loss of intramolecular water.

\section{Speculation}

It is hypothesized that elevated concentrations of calcium within glycoprotein secretions of patient with cystic fibrosis may substantially increase the density and insolubility of mucins, promoting the formation of mucous "plugs."

Mucous secretions of patients with cystic fibrosis are excessive in amount in salivary glands, bronchi, intestine, gall bladder, and cervix $(7,12,14)$. The calcium concentration in many of these secretions is also high, ranging from "slightly elevated" to over 100 -fold in excess of normal (12). It has been hypothesized that $\mathrm{Ca}$ may contribute to the formation of mucous "plugs" in glands and ducts by causing polymerization, aggregation, or gel formation of otherwise normal mucin macromolecules. A few studies have shown that $\mathrm{Ca}$ is responsible for aggregation of small salivary proteins $(4,5,13)$, but no studies have been performed to discover whether $\mathrm{Ca}$ changes the physical properties of purified mucin macromolecules of intestinal or bronchial origin.

Over the past few years a native goblet cell mucin has been purified in our laboratory from rat small intestine $(9,11)$. It resembles mucins purified by others from several human and animal organs $(1,4,6,1719)$, in that it is a polydisperse viscous glycoprotein rich in carbohydrate, containing high quantities of serine, threonine, and proline within the peptide core.

We have used rat goblet cell mucin as a model for the investigation of $\mathrm{Ca}-\mathrm{mucin}$ interaction. Previously we showed that rat mucin binds $C$ a ions, especially under conditions of low ionic strength, but that during binding Ca caused only minor physical changes in the mucin (8). In the present study we have measured the effects of $\mathrm{Ca}$ upon some of the physical properties of mucin in isotonic media in order to mimic more closely in viro conditions. Our results indicate that $\mathrm{Ca}$ may alter the three-dimensional architecture of mucin so as to increase its density and exclude water. It is postulated that this mechanism maly be involved in the formation of mucous plugs in cystic fibrosis.

\section{METHODS}

The preparation of goblet cell mucin ( $\mathrm{GCM}$ ) from rat intestine, radioactive labeling of the mucin using precursor $\left[{ }^{14} \mathrm{C}_{1}\right]$ glucosamine, the techniques of polyacrylamide disc gel electrophoresis, analytic ultracentrifugation, and measurement of solubility of the mucin have been described in detail in earlier publications $(8,9$, 11). Minor modifications and specific details are included as appropriate under Results.

Intestinal washings, when required for solubility experiments, were collected by washing the entire small intestine of each of 10 rats with approximately $20 \mathrm{ml} 0.15 \mathrm{M} \mathrm{NaCl}$. The washings were pooled, centrifuged at $4^{\circ}$ at $30,000 \times g$ for $15 \mathrm{~min}$ to remove particulate material, and the suernatant solutions saved. The soluble supernatant fluid was stored frozen in a dilute state or else concentrated isotonically 10 -fold by an Amicon Dia-Flo ultrafilter 